\title{
Analyze the Impact of Machining Environment on Human Energy in Indian Small Scale Industries
}

\author{
Dr.Mangesh R. Phate ${ }^{1}$, Dr.Manish S. Deshmukh ${ }^{2}$, Shraddha B. Toney ${ }^{3}$, Vikas R Phate ${ }^{4}$ \\ Associate Professor, Department of Mechanical Engg, AISSMSCOE, Pune, Maharashtra, India ${ }^{1,2}$ \\ Assistant Professor, Department of Computer Engg, SITS, Narhe, Pune, Maharashtra, India ${ }^{3}$ \\ Assistant Professor, Department of Electronics, Gov. Polytechnic, Murtizapur, Maharashtra, India ${ }^{4}$ \\ Email: mangeshphate03@gmail.com ${ }^{1}$, msdngp@gmail.com ${ }^{2}$,toneyshraddha@gmail.com ${ }^{3}$ vikas.phate13@gmail.com ${ }^{1}$
}

\begin{abstract}
In any cutting process, apart from obtaining the good surface quality, accurate dimensions, maximized productivity, metal removal rate and minimization of power consumed; human energy required during the machining process is also of most importance. In Indian scenario where majority of total machining operation are still executed manually which needs to be focused. A traditional machining process involves many process parameters which is directly or indirectly affects the human energy. This article explain an approach to formulate a Field Data Based Model (FDBM) to analyze the impact of various machining parameters on the human energy required during the machining of ferrous and non-ferrous material and develop a mathematical relation which simulate the real input and output data directly from the machining field where the work is actually being executed. . The findings indicate that the topic understudy is of great importance as no such approach of field data based mathematical simulation is adopted for the formulation of mathematical model for human energy required for the machining of ferrous and non- ferrous material.
\end{abstract}

Index Terms-Field data based model; optimization; Sensitivity; Reliability; Response surface model.

\section{INTRODUCTION}

This paper explains the mathematical simulation of manmachine system used in the traditional machining process used in Indian scenario. The purpose of developing such field data based model (FDBM) was to overcome the deficiencies in current method, for process improvement, process management and to reduce fatigue in the workers and musculoskeletal injuries. Extensive study has been conducted in the past to optimize the process parameters in any machining process to have the best product. Current investigation on turning process is a formulation of a field data based Methodology applied on the most effective machining field parameters i.e. operator parameter, cutting tool parameter, work piece parameter ,cutting process parameter , machine specifications and machining environment parameters.

Turning is a widely used machining process in manufacturing. Therefore, an optimal selection of cutting parameters to satisfy an economic objective within the constraints of turning operations is a very important task. Traditionally, the selection of cutting conditions for metal cutting is left to the machine operator Surface roughness, power consumption, material removal rate and productivity has received serious attention for many years. A considerable number of studies have investigated the general effects of the speed, feed, and depth of cut on the turning process. Some researchers studied on the machinability of aluminium-silicon alloys [2-6]. Liu et. al compared the influence of several factors (cutting speed, feed rate and depth of cut) on cutting force and surface roughness by orthogonal tests in turning $\mathrm{Si}-\mathrm{Al}$ alloy. The results showed that the surface roughness could be improved by using diamond tool [2]. Recently, in order to obtain reasonable cutting parameters in turning casting aluminium alloy ZL108.Wei, Wang, et al analyzed main influential factors of cutting force using carbide tool YG8.
The results indicated the depth of cut had great influence on stability of whole cutting process in rough machining. Armarego et. al (1969) investigated unconstrained machine-parameter optimization using differential calculus. Brewer et.al (1963) [3] carried out simplified optimum analysis for non-ferrous materials. For cast iron (CI) and steels, they employed the criterion of reducing the machining cost to a minimum. A number of monograms were worked out to facilitate the practical determination of the most economic machining conditions. They pointed out that the more difficult- to-machine materials have a restricted range of parameters over which machining can be carried out and thus any attempt at optimizing their costs are artificial. Brewer (1966) [3] suggested the use of Lagrangian multipliers for optimization of the constrained problem of unit cost, with cutting power as the main constraint. Walvekar et.al [10] (1970) discussed the use of geometric programming to selection of machine they optimized cutting speed and feed rate to yield minimum production cost. Petropoulos [6] (1973) investigated. Gopalakrishnan et.al (1991) described the design and development of an analytical tool for the selection of machine parameters in drilling. Geometric programming was used as the basic methodology to determine values for feed rate and cutting speed that minimize the total cost of machining SAE 1045 steel with cemented carbide tools of ISO P-10 grade. Surface finish and machine power were taken as the constraints while optimizing cutting speed and feed rate for a given depth of cut. Mangesh Phate et al [1824] (2012-2019) worked on artificial neural network and the dimensional analysis approach to model the machining and advanced machining performance of ferrous, nonferrous and composite materials. 


\section{International Journal of Research in Advent Technology, Vol.7, No.4, April 2019 \\ E-ISSN: 2321-9637 \\ Available online at www.ijrat.org}

\section{EXPERIMENTION}

Data sets contain information and the behavior of the process variables, often much more than can be learned from just looking at plots of those observed data. Mathematical models based on observed input and output data from real life situation ( Machining Process ) help us to gain new information and understanding from these data. Thus, it is not possible to plan such activities on the lines of design of experimentation [12], When one is studying any completely physical phenomenon but the phenomenon is very complex to the extent that it is not possible to formulate a logic based model correlating causes and effects of such a phenomenon, then one is required to go in for the field data based models. Hence the approach of formulating a field data based model is suggested to analysis the machining of ferrous and nonferrous material on traditional lathe machine. The methodology used to formulate the FDBM is described as follows.

\subsection{Identification of Process Variables}

The term variables are used in a very general sense to apply any physical quantity that undergoes change. If a physical quantity can be changed independent of the other quantities, then it is an independent variable. If a physical quantity changes in response to the variation of one or more number of independent variables, then it is termed as dependent or response variable. If a physical quantity that affects our test is changing in random and uncontrolled manner, then it is called an extraneous variable. The variables affecting the effectiveness of the phenomenon under consideration are operator data, single point cutting tool, lathe machine, work piece, process parameters and the environmental parameters. The dependent or the response variables in this case of turning operation is human energy. The list of various process variables which affects the machining phenomenon is as shown in table 1 (Annexure).

\subsection{Reduction of variables using Buckingham's Pi \\ Theorem}

According to the theories of engineering experimentation by $\mathrm{H}$. Schenck Jr. the choice of primary dimensions requires at least three primaries, but the analyst is free to choose any reasonable set he wishes, the only requirement being that his variables must be expressible in his system. There is really nothing basis or fundamental about the primary dimensions. For this case, the variables are expressed in mass $(\mathrm{M})$, length $(\mathrm{L})$, time $(\mathrm{T})$, temperature ( $\theta)$ and angle $(\Delta)$. Formulated pi terms are as shown in table 2 (Annexure).

\subsection{Experimental Planning}

- Test Envelop: To decide range of variation of an individual independent $\Pi$ term.

- Test Points: To decide \& specify values of independent $\Pi$ terms at which experimental setup be set during experimentation.

- Test Sequence: To decide the sequence in which the test points be set during experimentation

- Plan of Experimentation: Whether to adopt Classical Plan or Factorial Plan.
- $\quad$ Physical design of an experimental set up: this step included physical design of the experimental area for data collection.

- Execution of experimentation for data collection: this step included execution of the experimentation as per test planning and collection of data regarding causes (Inputs) and effects (Responses).

- Purification of experimentation data: this step included purification of the gathered data using statistical methods.

- Formulation of the field data based model.

- Model optimization, Sensitivity analysis and Reliability of the model.

The first six steps mentioned above constitute design of experimentation. The seventh step constitutes of model formulation where as eighth and ninth steps are respectively optimization and sensitivity and reliability of model.

\section{RESULT AND DISCUSSION}

Turning is carried on a traditional lathe that provides the power to turn the work piece at a given rotational speed and feed to the cutting tool at specified rate and depth of cut. Therefore three cutting parameters namely cutting speed, feed and depth of cut need to be determined in a turning operation The turning operations are accomplished using a cutting tool with high hardness help to sustain the high cutting forces and temperature during machining create a harsh environment for the cutting tool. The schematic view of the experimental set-up is shown in Figure1.

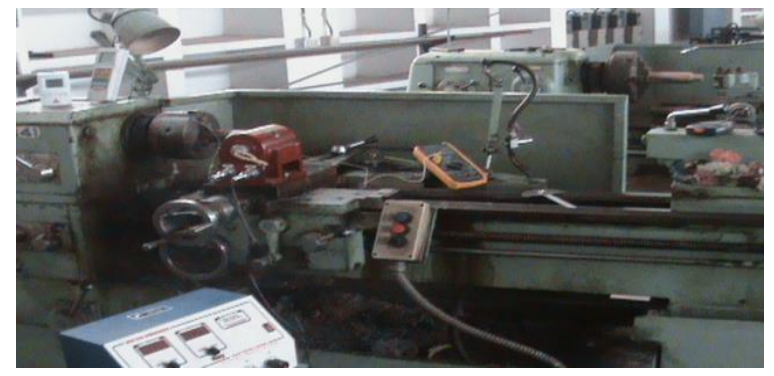

Figure 1 Experimental Setup for field data based model (FDBM) for human energy.

\subsection{Data Collection}

For multifactor experiments two types of plans viz. classical plan or full factorial and factorial plan are available, in this experimentation conventional plan of experimentation is recommended. In all data was collected from total 216 experiments of three material S.S.304, EN1A, EN8

\subsection{Purification of Data}

Out of these 216 observations, there are chances of some data being erroneous either from inputs or responses. Adopting techniques of rejecting the erroneous data, the observed data was purified for proceeding further with the step of Formulation of Models.

\subsection{Formulation of Field Data based Model}

It is necessary to correlate quantitatively various independent and dependent terms involved in this very 


\section{International Journal of Research in Advent Technology, Vol.7, No.4, April 2019 \\ E-ISSN: 2321-9637 \\ Available online at www.ijrat.org}

complex phenomenon. This correlation is nothing but a mathematical model as a design tool for such situation. The Mathematical model for step turning operations is as given below: For the machining operation Five independent pi terms $(\pi 1, \pi 2, \pi 3, \pi 4, \pi 5$ and $\pi 6)$ and one dependent pi terms $(\pi \mathrm{D} 1)$ were decided during experimentation and hence are available for the model formulation. Each dependent $\pi$ term is the function of the available independent terms.

$\Pi_{\mathrm{D} 1}=f\left(\Pi_{1}, \Pi_{2}, \Pi_{3}, \Pi_{4}, \Pi_{5}, \Pi_{6}\right)$

A probable exact mathematical form for the dimensional equations of the phenomenon could be relationships assumed to be of exponential form [5]. For example, the model representing the behavior of dependent pi term $\pi_{\mathrm{D} 1}$ with respect to various independent pi terms can be obtained as under.

$\Pi_{\mathrm{D} 1}=K_{1} \times \Pi_{1}^{a} \times \prod_{2}^{b} \times \prod_{3}^{c} \times \prod_{4}^{d} \times \prod_{5}^{e} \times \prod_{6}^{f}$

The values of exponent are a, b, c, d, e and $\mathrm{f}$ are established independently at a time, on the basic of data collected through classical experimentation. There are six unknown terms in the equation (2) curve fitting constant $\mathrm{K} 1$ and indices $\mathrm{a}, \mathrm{b}, \mathrm{c}, \mathrm{d}$, e and $\mathrm{f}$ to get the values of these unknowns we need minimum a set of five set of all unknown dimensionless pi terms

$$
Z=A+b X+C Y------
$$

The equation (2) can be brought in the form of equation (3) by taking $\log$ on both sides. Model of dependent pi term $\pi \mathrm{D} 1$ for surface roughness

$$
\Pi_{\mathrm{D} 1}=K_{1} \times \prod_{1}^{a} \times \prod_{2}^{b} \times \prod_{3}^{c} \times \prod_{4}^{d} \times \prod_{5}^{e} x \prod_{6}^{f}
$$

Taking log on the both sides of equation for $\pi$ D1

$$
\begin{aligned}
& L O G \prod_{\mathrm{D} 1}=L O G K_{1}+a L O G \prod_{1}+b L O G \prod_{2}+c L O G \prod_{3}+d L O G \prod_{4}+ \\
& e L O G \prod_{3}+e L O G \prod_{6}
\end{aligned}
$$

Let, $\mathrm{Z}=\log \pi \mathrm{D} 1, \mathrm{~K}=\log \mathrm{k} 1, \mathrm{~A}=\log \pi 1, \mathrm{~B}=\log \pi 2, \mathrm{C}$ $=\log \pi 3, \mathrm{D}=\log \pi 4, \mathrm{E}=\log \pi 5$,

Putting the values in equations 4 , the same can be written as

$$
Z=K+a X A+b \times B------
$$

Equation (7) is a regression equation of $\mathrm{Z}$ on $\mathrm{A}, \mathrm{B}, \mathrm{C}, \mathrm{D}$ and $\mathrm{E}$ in a dimensional co-ordinate system

$$
\begin{aligned}
& \sum Z=n \times K+a \times \sum A+b \times \sum B+c \times \sum C+d \times \sum D+e \times \sum E^{----} \\
& \sum Z A=K \sum A+a \times \sum A \times A+b \times \sum B \times A+c \times \sum C \times A+d \times \sum D \times A+e \times \sum E \times t \\
& -\sum Z B=K \sum B+a \times \sum A \times B+b \times \sum B \times B+c \times \sum C \times B+d \times \sum D \times B+e \times \sum E \times t
\end{aligned}
$$

$$
\begin{aligned}
& \sum Z C=K \sum C+a \times \sum A \times C+b \times \sum B \times C+c \times \sum C \times C+d \times \sum D \times C+e \times \sum E \times C \\
& \sum Z D=K \sum D+a \times \sum A \times D+b \times \sum B \times D+c \times \sum C \times D+d \times \sum D \times D+e \times \sum E \times D \\
& -\sum Z E=K \sum E+a \times \sum A \times E+b \times \sum B \times E+c \times \sum C \times E+d \times \sum D \times E+e \times \sum E \times E
\end{aligned}
$$

In the above set of equations the values of the multipliers $\mathrm{k}, \mathrm{a}, \mathrm{b}, \mathrm{c}, \mathrm{d}$ and e are substituted to compute the, a, b, c, d,e and $\mathrm{f}$ in the set of equations are calculated. After substituting these values in the equations (9) one will get a set of five equations, which are mutinously to get the values of $\mathrm{k}, \mathrm{a}, \mathrm{b}, \mathrm{c}, \mathrm{d}, \mathrm{e}$ and $\mathrm{f}$ The above equations can be verified in the matrix form and further values of $\mathrm{k}, \mathrm{a}, \mathrm{b}, \mathrm{c}$, $\mathrm{d}$ and e can be obtained by using matrix analysis.

$$
X 1=i n v(W) \times P 1
$$

Solving these equations using 'MATLAB' is given below. $\mathrm{W}=7 \times 7$ matrix multipliers of $\mathrm{k}, \mathrm{a}, \mathrm{b}, \mathrm{c}, \mathrm{d}$, e and $\mathrm{f}$ $\mathrm{P} 1=7 \times 1$ matrix of the terms on L H S and $\mathrm{X} 1=7 \mathrm{x} 1$ matrix of values of $\mathrm{k}, \mathrm{a}, \mathrm{b}, \mathrm{c}, \mathrm{d}, \mathrm{e}$ and $\mathrm{f}$ After solving we get the following models

1. Model 1 for Ferrous and Non ferrous materials with all independent pi terms

$$
\begin{aligned}
& \prod_{\mathrm{D} 1}=0.0002585 \times \Pi_{1}^{0.3855} \times \prod_{2}^{0.0179} \times \prod_{3}^{0.1965} \times \Pi_{4}^{-0.5341} \times \\
& \prod_{5}^{-0.0425} x \prod_{6}^{0.1271}
\end{aligned}
$$

2. Model 2 for Ferrous Material with all independent pi terms

$$
\begin{aligned}
& \prod_{\mathrm{D} 2}=0.001297 \times \Pi_{1}^{0.3354} \times \prod_{2}^{-0.0459} \times \prod_{3}^{0.2389} \times \Pi_{4}^{-0.4968} \\
& \times \prod_{5}^{0.0167} x \prod_{6}^{0.0762}
\end{aligned}
$$

3. Model 3 for Non ferrous Material with all independent pi terms

$$
\begin{aligned}
& \Pi_{\mathrm{D} 3}=0.00003968 \times \Pi_{1}^{0.4325} \times \Pi_{2}^{0.0072} \times \Pi_{3}^{0.2842} \\
& \times \Pi_{4}^{-0.5748} \times \prod_{5}^{-0.1957} \times \prod_{6}^{0.1576}
\end{aligned}
$$

The indices are as shown in figure 2.

\subsection{Reliability of the models}

Reliability of model is established by using the relation, reliability $=100-$ percentage mean error and mean error $=$. Sum $(x i * f i) / \operatorname{Sum}(f i)$, where, $x i$ is \% error and $f i$ is frequency of occurrence.

System reliability ( $R$ ) is given by the following equation (12)

$$
R=\left[\left(1-R_{1}\right) *\left(1-R_{2}\right) *\left(1-R_{3}\right)\right] * 100
$$



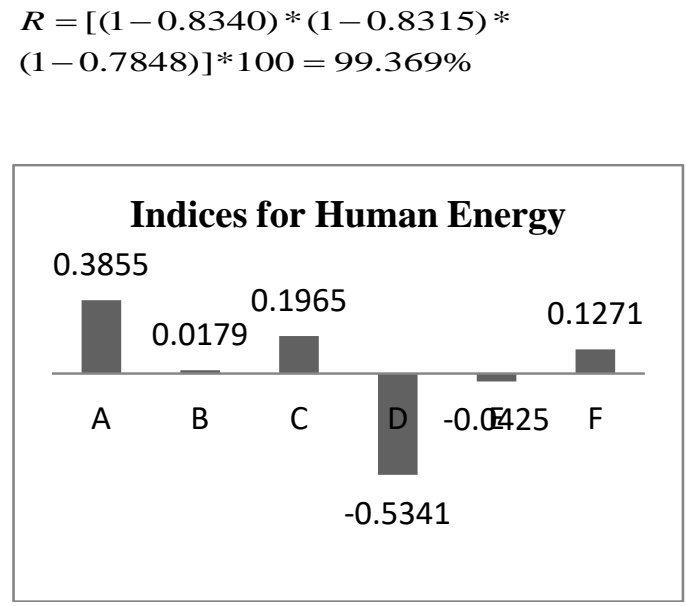

Fig 2a.

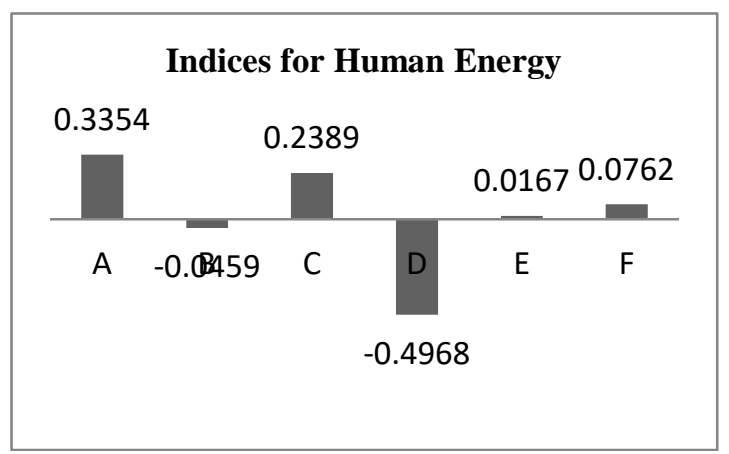

Fig 2b.

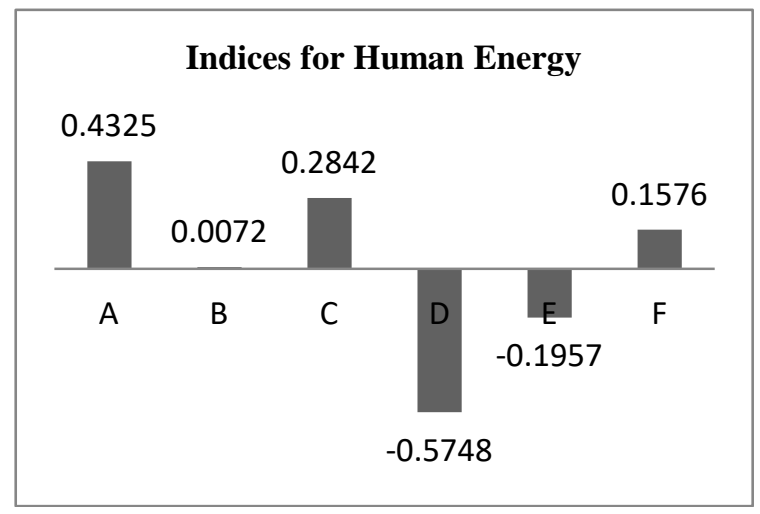

Fig 2c.

Figure 2. Indices for Human Energy Model Indices (a) For machining ferrous and Nonferrous Materials (b) For machining Ferrous material (c) For machining Non Ferrous material

\subsection{Optimization of the models}

The ultimate objective of this work is not merely developing the models but to find out best set of independent variables which will result in minimization of the objective functions. In this case There is one objective functions corresponding to surface roughness models. The objective functions for the surface roughness need to minimize. The models have non-linear form; hence, it is to be converted into a linear form for optimization purpose. This can be achieved by taking the log of both the sides of the model. The linear programming technique is applied which is detailed as below for turning Operation.

Taking $\log$ of both the sides of the Equation 8, we get, the objective function is

$\operatorname{MinZ}=\operatorname{LOG}(4.9268)+0.4075 \operatorname{LOG}\left(\Pi_{1}\right)+0.1562 \operatorname{LOG}\left(\Pi_{2}\right)+$ $0.3595 \operatorname{LOG}\left(\prod_{3}\right)-0.2591 \operatorname{LOG}\left(\prod_{4}\right)+0.0414 \operatorname{LOG}\left(\prod_{5}\right)$

Subject to the following constraints

$$
\begin{aligned}
& 1 X_{1}+0 X_{2}+0 X_{3}+0 X_{4}+0 X_{5} \leq L O G\left(\operatorname{Max} \prod_{1}\right), \\
& 1 X_{1}+0 X_{2}+0 X_{3}+0 X_{4}+0 X_{5} \geq \operatorname{LOG}\left(\operatorname{Min} \prod_{1}\right) \text {, } \\
& 0 X_{1}+1 X_{2}+0 X_{3}+0 X_{4}+0 X_{5} \leq L O G\left(\operatorname{Max} \prod_{2}\right) \\
& 0 X_{1}+1 X_{2}+0 X_{3}+0 X_{4}+0 X_{5} \geq L O G\left(\operatorname{Min} \Pi_{2}\right), \\
& 0 X_{1}+0 X_{2}+1 X_{3}+0 X_{4}+0 X_{5} \leq L O G\left(\operatorname{Max}_{3}\right), \\
& 0 X_{1}+0 X_{2}+1 X_{3}+0 X_{4}+0 X_{5} \geq \operatorname{LOG}\left(\operatorname{Min} \prod_{3}\right) \\
& 0 X_{1}+0 X_{2}+0 X_{3}+1 X_{4}+0 X_{5} \leq L O G\left(\operatorname{Max} \prod_{4}\right), \\
& 0 X_{1}+0 X_{2}+0 X_{3}+1 X_{4}+0 X_{5} \geq L O G\left(\operatorname{Min} \prod_{4}\right), \\
& 0 X_{1}+0 X_{2}+0 X_{3}+0 X_{4}+1 X_{5} \leq L O G\left(\operatorname{Max} \prod_{5}\right) \\
& 0 X_{1}+0 X_{2}+0 X_{3}+0 X_{4}+1 X_{5} \geq \operatorname{LOG}\left(\operatorname{Min} \prod_{5}\right), \\
& 0 X_{1}+0 X_{2}+0 X_{3}+0 X_{4}+1 X_{5} \leq L O G\left(\operatorname{Max} \prod_{5}\right), \\
& 0 X_{1}+0 X_{2}+0 X_{3}+0 X_{4}+1 X_{5} \geq \operatorname{LOG}\left(\operatorname{Min} \prod_{5}\right)
\end{aligned}
$$

On solving the above problem by using MS solver we get values of $\mathrm{X} 1, \mathrm{X} 2, \mathrm{X} 3, \mathrm{X} 4, \mathrm{X} 5$ and $\mathrm{Z}$. Thus $\mathrm{CD} 1 \mathrm{~min}$ $=$ Antilog of $\mathrm{Z}$ and corresponding to this value of the ID1min the values of the independent $\pi$ terms are obtained by taking the antilog of $\mathrm{X} 1, \mathrm{X} 2, \mathrm{X} 3, \mathrm{X} 4, \mathrm{X} 5$, X6 and $Z$. The optimized values are tabulated in table 5 (Annexure).

\subsection{Sensitivity analysis of the models}

The influence of the various independent $\pi$ terms has been studied by analyzing the indices of the various $\pi$ terms in the models. Through the technique of sensitivity analysis, the change in the value of a dependent $\pi$ term caused due to an introduced change in the value of individual $\pi$ term is evaluated. In this case, of change of $\pm 10 \%$ is introduced in the individual independent $\pi$ term independently (one at a time).Thus, total range of the introduced change is \pm 20 $\%$. The effect of this introduced change on the change in the value of the dependent $\pi$ term is evaluated.The average values of the change in the dependent $\pi$ term due to the introduced change of $\pm 10 \%$ in each independent $\pi$ term. This defines sensitivity. The total $\%$ change in output for $\pm 10 \%$ change in input is shown in Table 4

The graphical distribution of the sensitivity analysis of the formulated model with respect to different pi terms is shown in figure 2. 


\section{VALIDATION OF MODEL THROUGH RESPOSNE SURFACE MODELS}

Response surface methodology (RSM) consists of a group of mathematical and statistical techniques used in the development of an adequate functional relationship between a response of interest, $\mathrm{Z}$, and a number of associated control (or input) variables denoted by A, B, $\mathrm{C}, \mathrm{D}, \mathrm{E} \& \mathrm{~F}$. In general, such relationship is unknown but can be approximated by fitting a best fit polynomial model .

1. For ferrous and nonferrous material $Z 1=39.73-4.518 X-1.102 * Y+0.06778 * X^{2}+0.502 * X * Y-$ $0.4423 * Y^{2}+0.00210 * X^{3}-0.1878 * X^{2} * Y+0.01879 * X * Y^{2}$ $-0.0007231 * Y^{3}$

2. For ferrous material

$$
\begin{aligned}
& Z 1=142.2-23.82 X-14.55 * Y+1.271 * X^{2}-1.452 * X * Y \\
& +0.0 .3589 * Y^{2}-0.02247 * X^{3}-0.04478 * X^{2} * Y \\
& +0.03006 * X * Y^{2}+0.01322 * Y^{3}
\end{aligned}
$$

$$
\begin{aligned}
& \text { 3.For Nonferrous material } \\
& Z 1=39.22-22.48 X+35.67 * Y+1.253 * X^{2} \\
& -1.223 * X * Y-1.875 * Y^{2}-0.01875 * X^{3}+ \\
& 0.0037416 * X^{2} * Y+0.05346 * X * Y^{2}+0.01284 * Y^{3}
\end{aligned}
$$

Where $\mathrm{X}=\mathrm{A} * \mathrm{~B} * \mathrm{C}$ and $\mathrm{Y}=\mathrm{D} * \mathrm{E} * \mathrm{~F}$

The response surface are as shown in figure 4 (Annexure).

\section{CONCLUSION}

In this study, a generalized field data based model was developed to simulate the dry turning process for ferrous and nonferrous materials. The approach of generalized model formulation model provided an excellent and simple way to analyze the engineering complex process where the impact of field data is dominating the performance .It can be seen from the equation that this model of pi terms containing surface roughness as response variable.

It can be seen from the Equation (16-18) and Figure 2 influence of indices of independent $\pi$ terms on response variable that this was a model of $\pi$ term human energy as a response variable. The following primary conclusions appear to be justified by the above model.

1) For the ferrous and nonferrous material, the absolute index of $\pi 1$ was the highest i.e. 0.3855 . Thus $\pi 1$ the term related to the lathe machine operator data was the most influencing $\pi$ term in the model. The value of this index was positive indicating that $\pi \mathrm{D} 1$ increases as this $\pi$ term increases or otherwise. The absolute index of $\pi 4$ was the lowest i.e. -0.5341 . Thus $\pi 4$ the term related to cutting process parameters was the least influencing $\pi$ term in the model. The curve fitting constant is 0.0002585 . This curve fitting constant represents collective effect of certain immeasurable parameters which have influence on the human energy.

2) For the ferrous material, the absolute index of $\pi 1$ was the highest i.e. 0.3354 . Thus $\pi 1$ the term related to the lathe machine operator data was the most influencing $\pi$ term in the model. The value of this index was positive indicating that $\pi \mathrm{D} 1$ increases as this $\pi$ term increases or otherwise. The absolute index of $\pi 4$ was the lowest i.e. -0.4968 . Thus $\pi 4$ the term related to cutting process parameters was the least influencing $\pi$ term in the model. The curve fitting constant is 0.001297. This curve fitting constant represents collective effect of certain immeasurable parameters which have influence on the human energy.

3) For the nonferrous material, the absolute index of $\pi 1$ was the highest i.e. 0.4325 . Thus $\pi 1$ the term related to the lathe machine operator data was the most influencing $\pi$ term in the model. The value of this index was positive indicating that $\pi \mathrm{D} 1$ increases as this $\pi$ term increases or otherwise. The absolute index of $\pi 4$ was the lowest i.e. -0.5748 . Thus $\pi 4$ the term related to cutting process parameters was the least influencing $\pi$ term in the model. The curve fitting constant is 0.00003968 . This curve fitting constant represents collective effect of certain immeasurable parameters which have influence on the human energy.

4) Sensitivity analysis of dry cutting operation indicates single point cutting tool and the cutting process parameters are most sensitive and work piece parameter, lathe machine specification as well as machining environmental parameters are least sensitive for model $\Pi D 1$ and hence needs strong improvement.

5) The comparison of experimental, mathematical model, Single Degree polynomial Response surface model( Analytical) and Response Surface three degree polynomial model ( Graphical) is shown in the figure 5a- 5c.

6) The comparison of indices of various input variables for human energy Model in case of ferrous \& nonferrous material, ferrous material and nonferrous materials is as shown in fig 6(Annexure).

The comparison of sensitivity of various input variables for human energy Model in case of ferrous \& nonferrous material, ferrous material and nonferrous materials is as shown in fig 7 (Annexure).

\section{Acknowledgement}

Authors acknowledged the Machine shop, Shivne, Pune, Maharashtra, India for the cooperation and permission for carry out the research work. 


\section{REFERENCES}

[1] Iwona, P.,Christina, B.,Hamid, R. K., \& Peter, M.(2009). Mathematical model of micro turning process. International Journal of Advanced Manufacturing Technology,45(1), 33-40.

[2] Kahraman,S.,(2009).The use of response surface methodology for the prediction and analysis of surface roughness of AISI 4140 steel. Materials and technology,13(6), 267-270.

[3] Kumar,A., Kumar,S., \& Garg,R.,(2011).Statistical Modeling of surface roughness in turning process. International Journal of Engineering Science and Technology (IJEST), 3(5), 4246-4252.

[4] Jeffrey B., Dahmus,S., and Timothy, G.,(2004). An environmental analysis of machining, ASME International Mechanical Engineering Congress and $R D \& D$ Expo,13-19.

[5] Soleimanimehr,H.,

Nategh,M.J., Amini,S.,(2009).Modeling of Surface Roughness in Vibration Cutting by Artificial Neural Network, World Academy of Science, Engineering and Technology,52, 386-391.

[6] Neelakanth,V., Gaitonde,S. R., Karnik,L. F.,\&Davim,J.P.,(2011).Performance comparison of conventional and wiper ceramic inserts in hard turning through artificial neural network modeling, International Journal of Advanced manufacturing Technology, 52,101-114.

[7] Petropoulos G., Ntziantzias I., \& Anghel, C.,(2005)International Conference on Experiments/ Process/ System Modelling/ Simulation/Optimization, Athens, 25-34.

[8] H. Schenck Jr., Theories of Engineering a experimentation,McGraw Hill Book Co ,New York, 1954,40-50.

[9] Sundaram, R.M., (1978)An application of goal programming technique in metal cutting, International Journal of Production Research, 375-382.

[10] Agapiou, J.S., (1992), The optimization of machining operations based on a combined criterion, Part 1 The use of combined objectives in single-pass operations, Part 2: Multi-pass operations. J. Eng Ind., Trans. ASME, 1(14),500-513.

[11]Brewer, R.C,. \& Rueda, R.,(1963),A simplified approach to the optimum selection of machining parameters, Eng Dig,133-150.

[12] Petropoulos, P.G.,(1973), Optimal selection of machining rate Variable by geometric programming. $J$ Prod. Res., 1973,305-314.

[13]Phate, M.R., Tatwawadi V.H., Modak J.P.,(2012), Formulation of A Generalized Field Data Based Model For The Surface Roughness of Aluminum 6063 In Dry Turning Operation, New York Science Journal, 5(7),38-46 .

[14] Tatwawadi, V.H., Modak, J.P., \& Chibule, S.G.,(2010). Mathematical Modeling and simulation of working of enterprise manufacturing electric motor, International Journal of Industrial Engineering,341351.

[15] Walvekar, A.G., \& ,Lambert B.K., (1970),An application of geometric programming to machining variable selection. Int. J.Prod. Res.,38-45.

[16] Gilbert W.W., Economics of machining. In Machinin - Theory and practice. Am. Soc. M1950,476-480.

[17] Muwell K.F.H., Nature of Ergonomics, Ergonomics (Man In His Working Environment), Chapman and Hall, London, New York, 1956,PP.69-85.

[18] Phate, M., Toney, S., (2016). Formulation of artificial neural network (ANN) based model for the dry machining of ferrous \& non-ferrous material used in Indian small scale industries. International Journal of Materials Science and Engineering, 4(3),145-160. doi: 10.17706/ijmse.2016.4.3.145-160.

[19]Phate, M., Tatwawadi, V., \& Modak, J., (2013) Modeling and simulation of productivity in the turning of ferrous and nonferrous material using artificial neural network and response surface methodology. Research Journal of Engineering Sciences, 2 (3),3744. http://www.isca.in/IJES/Archive/v2/i3/8.ISCARJEngS-2013-027.pdf.

[20] Phate, M., Tatwawadi, V., (2014). ANN based model development for material removal rate in dry turning in Indian context. World academy of Science, Engineering and Technology International Journal of Mechanical, Aerospace, Industrial, Mechatronic and Manufacturing Engineering, 8 (1),130-135. http://waset.org/publications/9997427.

[21]Phate, M., Tatwawadi, V., (2015). Mathematical Model of Material Removal rate and Power Consumption for Dry Turning of Ferrous Material using Dimensional Analysis in Indian Prospective. Jordon Journal of Mechanical and Industrial Engineering, 9 (1),351-362.jjmie.hu.edu.jo/vol91/JJMIE_-25-14-01.

[22] Phate, M., Toney, S., (2019). Modeling and prediction of WEDM performance parameters for $\mathrm{Al} / \mathrm{SiCp} \mathrm{MMC}$ using dimensional analysis and artificial neural network. Engineering Science and Technology, an International Journal, $22 \quad$ (2),468476.https://doi.org/10.1016/j.jestch.2018.12.002.

[23] Phate ,M., Toney, S., \& Phate ,V., (2019). Analysis of machining parameters in WEDM of $\mathrm{Al} / \mathrm{Sicp} 20$ MMC using Taguchi -based Grey -Fuzzy Approach. Hindawi's, Modelling and Simulation in Engineering, Article ID 1483169, 13 pages, 2019. https://doi.org/10.1155/2019/1483169.

[24]Phate ,M., Toney, S., \& Phate ,V., (2019). Optimization Performance Parameters of OHNS Die Steel using Dimensional Analysis Integrated with Desirability Function. International Journal of Industrial Engineering and Production Research, 30 (1),11-23. http://ijiepr.iust.ac.ir/article-1-877-en.html. 
International Journal of Research in Advent Technology, Vol.7, No.4, April 2019

E-ISSN: 2321-9637

Available online at www.ijrat.org

\section{Annexure}

Table 1. List of various dependent and independent Variables

\begin{tabular}{|c|c|c|c|c|}
\hline S.N & Description & Symbol & Nature & Dimensions \\
\hline 1 & $\begin{array}{l}\text { Anthropometric } \\
\text { dimensions ratio } \\
\text { of the operator. }\end{array}$ & An & Independent & $M^{0} L^{0} \quad T^{0} \quad \theta^{0} \quad \Delta^{0}$ \\
\hline 2 & $\begin{array}{l}\text { Weight of the } \\
\text { operator. }\end{array}$ & $\mathrm{W}_{\mathrm{p}}$ & Independent & $\mathbf{M}^{1} \mathbf{L}^{0} \mathrm{~T}^{0} \theta^{0} \Delta^{0}$ \\
\hline 3 & $\begin{array}{l}\text { Age of the } \\
\text { operator. }\end{array}$ & AGP & Independent & $M^{0} L^{0} T^{1} \theta^{0} \Delta^{0}$ \\
\hline 4 & Experience & EX & Independent & $M^{0} L^{0} T^{1} \theta^{0} \Delta^{0}$ \\
\hline 5 & Skill rating & SK & Independent & $M^{0} L^{0} \quad T^{0} \quad \theta^{0} \quad \Delta^{0}$ \\
\hline 6 & $\begin{array}{l}\text { Educational } \\
\text { Qualification }\end{array}$ & EDU & Independent & $M^{0} L^{0} T^{0} \quad \theta^{0} \Delta^{0}$ \\
\hline 7 & $\begin{array}{l}\text { Psychological } \\
\text { Distress }\end{array}$ & PS & Independent & $M^{0} L^{0} T^{0} \quad \theta^{0} \Delta^{0}$ \\
\hline 8 & $\begin{array}{l}\text { Systolic Blood } \\
\text { pressure }\end{array}$ & SBP & Independent & $M^{0} L^{0} T^{1} \quad \theta^{0} \Delta^{0}$ \\
\hline 9 & $\begin{array}{l}\text { Diastolic } \\
\text { pressure }\end{array}$ & DBP & Independent & $M^{0} L^{0} T^{0} \quad \theta^{0} \Delta^{0}$ \\
\hline 10 & $\begin{array}{lr}\text { Blood } & \text { Sugar } \\
\text { Level } & \text { during } \\
\text { Working } & \end{array}$ & BSG & Independent & $M^{1} L^{-3} T^{0} \theta^{0} \Delta^{0}$ \\
\hline 11 & $\begin{array}{ll}\text { Cutting } & \text { Tool } \\
\text { angles ratio. } & \end{array}$ & CTAR & Independent & $M^{0} L^{0} \quad T^{0} \quad \theta^{0} \Delta^{0}$ \\
\hline 12 & Tool nose radius & $\mathrm{R}$ & Independent & $M^{0} L^{1} \quad T^{0} \quad \theta^{0} \quad \Delta^{0}$ \\
\hline 13 & $\begin{array}{l}\text { Tool overhang } \\
\text { length }\end{array}$ & Lo & Independent & $M^{0} L^{1} T^{0} \quad \theta^{0} \Delta^{0}$ \\
\hline 14 & Approach angle & A & Independent & $M^{0} L^{0} \quad T^{0} \quad \theta^{1} \quad \Delta^{0}$ \\
\hline 15 & Setting angle & B & Independent & $M^{0} L^{0} T^{0} \quad \theta^{1} \Delta^{0}$ \\
\hline 16 & $\begin{array}{lr}\text { Single } & \text { point } \\
\text { cutting } & \text { tool } \\
\text { Hardness } & \end{array}$ & $\mathrm{BHN}$ & Independent & $M^{0} L^{0} T^{0} \quad \theta^{0} \Delta^{0}$ \\
\hline 17 & $\begin{array}{l}\text { Lip or Nose angle } \\
\text { of tool }\end{array}$ & LP & Independent & $M^{0} L^{0} \quad T^{0} \quad \theta^{1} \Delta^{0}$ \\
\hline 18 & Wedge angle & WG & Independent & $M^{0} L^{0} T^{0} \quad \theta^{1} \Delta^{0}$ \\
\hline 19 & Shank Length & $\mathrm{LS}$ & Independent & $M^{0} L^{1} T^{0} \quad \theta^{0} \Delta^{0}$ \\
\hline 20 & $\begin{array}{l}\text { Total length of the } \\
\text { tool }\end{array}$ & LT & Independent & $M^{0} L^{1} T^{0} \quad \theta^{0} \Delta^{0}$ \\
\hline 21 & Tool shank width & SB & Independent & $M^{0} L^{1} T^{0} \quad \theta^{0} \Delta^{0}$ \\
\hline 22 & Tool shank Height & $\mathrm{SH}$ & Independent & $M^{0} L^{1} T^{0} \quad \theta^{0} \Delta^{0}$ \\
\hline 23 & $\begin{array}{l}\text { Work piece } \\
\text { hardness }\end{array}$ & BHNW & Independent & $M^{0} L^{0} T^{0} \quad \theta^{0} \Delta^{0}$ \\
\hline 24 & $\begin{array}{l}\text { Weight of the } \\
\text { raw work piece. }\end{array}$ & $\mathrm{W}$ & Independent & $M^{1} L^{0} T^{0} \quad \theta^{0} \Delta^{0}$ \\
\hline 25 & $\begin{array}{l}\text { Ultimate Shear } \\
\text { stress of the } \\
\text { workpiece } \\
\text { material }\end{array}$ & $\sigma_{\text {sut }}$ & Independent & $M^{1} L^{-1} T^{-2} \theta^{0} \Delta^{0}$ \\
\hline 26 & $\begin{array}{l}\text { Density of the } \\
\text { workpiece } \\
\text { material }\end{array}$ & DST & Independent & $M^{1} L^{-3} T^{0} \theta^{0} \Delta^{0}$ \\
\hline 27 & Length of the raw & LR & Independent & $M^{0} L^{1} T^{0} \quad \theta^{0} \Delta^{0}$ \\
\hline
\end{tabular}


International Journal of Research in Advent Technology, Vol.7, No.4, April 2019

E-ISSN: 2321-9637

Available online at www.ijrat.org

28

29

30

31

32

33

34

40

41

42

43

44

workpiece

Diameter of the DR

raw workpiece

Cutting Speed VC

Feed f

Depth of cut D

Cutting force $\quad \mathrm{FC}$

Tangential Force. FT

Spindle revolution N

Machine MSP

Specification ratio

Power of the HP

Machine motor

Weight of the Wm

machine

Age of the AGM

machine

Atmospheric $\Phi$

Humidity

Atmospheric

Temperature

Air Flow

Light Intensity

Sound level

Human Energy
DT

Vf

LUX

DB

HE
Independent

Independent

Independent

Independent

Independent

Independent

Independent

Independent

Independent

Independent

Independent

Independent

Independent

Independent

Independent

Independent

Dependent
$M^{0} L^{1} T^{0} \quad \theta^{0} \Delta^{0}$

$M^{0} L^{1} T^{-1} \theta^{0} \Delta^{0}$

$M^{0} L^{1} T^{0} \quad \theta^{0} \Delta^{0}$

$M^{0} L^{1} T^{0} \theta^{0} \Delta^{0}$

$M^{1} L^{1} T^{-2} \theta^{0} \Delta^{0}$

$M^{1} L^{1} T^{-2} \theta^{0} \Delta^{0}$

$M^{0} L^{0} T^{-1} \theta^{0} \Delta^{0}$

$M^{0} L^{0} T^{0} \theta^{0} \Delta^{0}$

$M^{1} L^{2} T^{-3} \theta^{0} \Delta^{0}$

$M^{1} L^{0} T^{0} \theta^{0} \Delta^{0}$

$M^{0} L^{0} T^{1} \quad \theta^{0} \Delta^{0}$

$M^{0} L^{0} T^{0} \quad \theta^{0} \Delta^{0}$

$M^{0} L^{0} T^{0} \quad \theta^{0} \Delta^{1}$

$M^{0} L^{1} T^{-1} \theta^{0} \Delta^{0}$

$M^{1} L^{0} T^{-4} \theta^{0} \Delta^{0}$

$M^{0} L^{0} \quad T^{0} \theta^{0} \Delta^{0}$

$M^{1} L^{2} T^{-2} \theta^{0}$

$\Delta^{0}$

Table 2. Final Independent and Dependent dimensionless Pi term

\begin{tabular}{|c|c|c|c|}
\hline S.N & $\begin{array}{l}\text { Independent } \\
\text { dimensionless } \\
\text { ratio } \\
\pi_{1}\end{array}$ & $\pi_{1}=\mathrm{An} * \mathrm{SBP} * \mathrm{SK} * \mathrm{Ag} * \mathrm{Wp} * \mathrm{SPO} 2 / \mathrm{DBP} * \mathrm{PS} * \mathrm{EDU} * \mathrm{EX} * \mathrm{BSG}^{*} \mathrm{D}^{3}$ & $\begin{array}{l}\text { Nature of } \\
\text { Basic Physical } \\
\text { Quantities } \\
\text { Machine } \\
\text { operator data }\end{array}$ \\
\hline 2 & $\pi_{2}$ & $\pi_{2}=\mathrm{AR} * \mathrm{r} * \beta * \mathrm{BHNT} * \mathrm{LT} * \mathrm{LP} * \mathrm{LS} / \alpha * \mathrm{LO} * \mathrm{SW} * \mathrm{SH} * \mathrm{WG}$ & $\begin{array}{l}\text { Single point } \\
\text { cutting tool }\end{array}$ \\
\hline 3 & $\pi_{3}$ & $\pi_{3}=\mathrm{BHNW} * \mathrm{~W}$ raw $^{*} \mathrm{LR} * \tau / \mathrm{D} * \mathrm{FC} * \mathrm{DST} * \mathrm{DR}$ & $\begin{array}{l}\text { Work piece } \\
\text { material }\end{array}$ \\
\hline 4 & $\pi_{4}$ & $\pi_{4}=\mathrm{f} * \mathrm{FT} * \mathrm{~N} * \mathrm{Temp}_{\mathrm{wp}} * \mathrm{VB}$ Tool $/ \mathrm{VB}_{\text {Machine }} * \mathrm{FC} * \mathrm{VC}$ & $\begin{array}{l}\text { Cutting process } \\
\text { parameters }\end{array}$ \\
\hline 5 & $\pi_{5}$ & $\pi_{5}=\mathrm{SP} * \mathrm{P}_{\mathrm{HP}} * \mathrm{~W}_{\mathrm{m} / \mathrm{c}} / \mathrm{AGM}^{*} \mathrm{FC}^{2}$ & $\begin{array}{l}\text { Machine } \\
\text { Specification }\end{array}$ \\
\hline 6 & $\pi_{6}$ & $\pi_{6}=\mathrm{HUM} * \mathrm{DTO} * \mathrm{~V}_{\mathrm{f}} * \mathrm{DB} * \mathrm{VC} * \mathrm{FC} / \mathrm{LUX} * \mathrm{D}^{3}$ & $\begin{array}{l}\text { Working } \\
\text { environmental } \\
\text { parameters }\end{array}$ \\
\hline 7 & $\pi_{\mathrm{D} 1}$ & $\mathrm{HE} / \mathrm{D} * \mathrm{FC}$ & Human Energy \\
\hline
\end{tabular}


International Journal of Research in Advent Technology, Vol.7, No.4, April 2019

E-ISSN: 2321-9637

Available online at www.ijrat.org

Table 3.Optimized values of response variables for dry turning operation

\begin{tabular}{|c|c|c|c|c|c|c|c|c|}
\hline \multicolumn{4}{|c|}{ Ferrous and Nonferrous Material } & \multicolumn{2}{|c|}{ Ferrous material } & \multicolumn{3}{|c|}{ Nonferrous Material } \\
\hline $\begin{array}{l}\mathrm{Pi} \\
\text { terms }\end{array}$ & $\begin{array}{l}\text { Optimum } \\
\text { Pi term }\end{array}$ & $\begin{array}{l}\text { Actual } \\
\text { term }\end{array}$ & $\begin{array}{l}\mathrm{Pi} \\
\text { terms }\end{array}$ & $\begin{array}{l}\text { Optimum } \\
\text { Pi term }\end{array}$ & Actual Pi term & $\begin{array}{l}\mathrm{Pi} \\
\text { terms }\end{array}$ & $\begin{array}{l}\text { Optimum } \\
\text { Pi term }\end{array}$ & $\begin{array}{ll}\text { Actual } & \mathrm{Pi} \\
\text { term }\end{array}$ \\
\hline $\mathrm{Z1}$ & -0.43947 & 0.363521 & $\mathrm{Z1}$ & -0.24903 & 0.5636078 & $\mathrm{Z1}$ & -0.51803 & 0.3033 \\
\hline A & 14.0243 & $1.051 \mathrm{e}+14$ & A & 14.02429 & $1.0575244 \mathrm{e}+14$ & A & 14.4894 & $3.086 \mathrm{e}+14$ \\
\hline B & 2.26068 & 182.25523 & $\mathrm{~B}$ & 4.076405 & $1.1924153 \mathrm{e}+4$ & $\mathrm{~B}$ & 2.26068 & 182.25 \\
\hline $\mathrm{C}$ & 4.34298 & $2.2069 \mathrm{e}+4$ & $\mathrm{C}$ & 4.544880 & $3.5065102 \mathrm{e}+4$ & $\mathrm{C}$ & 4.34298 & $2.2069 \mathrm{e}+4$ \\
\hline $\mathrm{D}$ & 0.05754 & 1.14166845 & $\mathrm{D}$ & 0.057544 & 1.1416789665 & $\mathrm{D}$ & -0.2424 & 0.57226 \\
\hline $\mathrm{E}$ & 0.1426615 & 1.3888696 & $\mathrm{E}$ & -6.57764 & $3.7811205 \mathrm{e}+6$ & $\mathrm{E}$ & -0.18207 & 0.65755 \\
\hline $\mathrm{F}$ & 12.25411 & $1.7924 \mathrm{e}+12$ & $\mathrm{~F}$ & 12.25411 & $1.7952624 \mathrm{e}+12$ & $\mathrm{~F}$ & 12.3491 & $2.231 \mathrm{e}+12$ \\
\hline
\end{tabular}

Table 4. Sensitivity analysis and Indices of model :

\begin{tabular}{|c|c|c|c|c|c|c|c|c|c|}
\hline \multicolumn{4}{|c|}{ Ferrous and Nonferrous Material } & \multicolumn{3}{|c|}{ Ferrous material } & \multicolumn{3}{|c|}{ Nonferrous Material } \\
\hline $\begin{array}{l}\mathrm{Pi} \\
\text { terms }\end{array}$ & $\%$ Change & $\begin{array}{l}\text { Indices Of } \\
\text { the Model }\end{array}$ & $\begin{array}{l}\mathrm{Pi} \\
\text { terms }\end{array}$ & $\%$ Change & $\begin{array}{l}\text { Indices } \\
\text { Model }\end{array}$ & Of the & $\begin{array}{l}\mathrm{Pi} \\
\text { terms }\end{array}$ & $\%$ Change & $\begin{array}{l}\text { Indices Of } \\
\text { the Model }\end{array}$ \\
\hline П1 & -246.841 & 0.3855 & $\prod 1$ & -377.775 & & 0.3354 & П1 & -241.939 & 0.4325 \\
\hline$\Pi 2$ & -1.841 & 0.0179 & $\Pi 2$ & 15.027 & & -0.0459 & П2 & -0.6284 & 0.0072 \\
\hline П3 & -38.837 & 0.1965 & П3 & -87.2777 & & 0.2389 & $\prod 3$ & -47.6521 & 0.2842 \\
\hline$\prod 4$ & 1.39869 & -0.5341 & $\prod 4$ & 2.296 & & -0.4968 & П4 & -4.532 & -0.5748 \\
\hline П5 & 0.2759 & -0.0425 & П5 & 8.822201 & & 0.0167 & П5 & -1.3756 & -0.1957 \\
\hline П6 & -70.88 & 0.1271 & П6 & -74.9941 & & 0.0762 & П6 & -75.138 & 0.1576 \\
\hline
\end{tabular}

Table 5. Validation results of Human Energy for ferrous and nonferrous materials

\begin{tabular}{|c|c|c|c|c|}
\hline Observation no. & Actual HE & Calculated HE & Linear RSM HE & Best Fit RSM HE \\
\hline 1 & 2.108342 & 2.341209952 & 2.08932038 & 2.06525036 \\
\hline 2 & 1.480574 & 1.769944371 & 1.61965808 & 1.60208985 \\
\hline 3 & 1.219175 & 1.32941068 & 1.34772075 & 1.32940619 \\
\hline 112 & 1.302734 & 1.268973805 & 1.18891511 & 1.17832362 \\
\hline 113 & 1.394131 & 1.443234548 & 1.31713973 & 1.32052638 \\
\hline 114 & 0.875416 & 0.799882965 & 0.88476113 & 0.8771478 \\
\hline 543 & 2.008643 & 1.733911788 & 1.42691473 & 1.40581341 \\
\hline 544 & 1.859629 & 1.474193639 & 1.24578636 & 1.2186115 \\
\hline 545 & 1.441963 & 1.087552446 & 0.93264883 & 0.92527436 \\
\hline 546 & 1.568178 & 1.047030012 & 0.93307735 & 0.92570911 \\
\hline
\end{tabular}

Table 6. Validation results of Human Energy for ferrous materials

\begin{tabular}{|c|c|r|r|c|}
\hline Observation no. & Actual HE & Calculated HE & Linear RSM HE & Best Fit RSM HE \\
\hline 1 & 2.108342 & 2.312656757 & 2.072305787 & 2.092324527 \\
\hline 2 & 1.480574 & 1.764998839 & 1.577008235 & 1.602256193 \\
\hline 3 & 1.219175 & 1.352613804 & 1.291035487 & 1.309558257 \\
\hline 120 & 0.553474 & 0.761859285 & 0.887304658 & 0.874184856 \\
\hline 121 & 1.042157 & 1.158164537 & 1.241405382 & 1.20736758 \\
\hline 122 & 0.564315 & 0.577886868 & 0.743926694 & 0.751729989 \\
\hline 327 & 1.370924 & 1.376976478 & 1.269519767 & 1.283333176 \\
\hline 328 & 1.680405 & 1.628207315 & 1.481675686 & 1.518130863 \\
\hline 329 & 1.869484 & 1.849628546 & 1.730658899 & 1.820725949 \\
\hline 330 & 1.825359 & 1.86514859 & 1.723199032 & 1.818599374 \\
\hline
\end{tabular}

Table 7. Validation results of Human Energy for nonferrous materials

\begin{tabular}{|c|c|c|c|c|}
\hline Observation no. & Actual HE & Calculated HE & Linear RSM HE & Best Fit RSM HE \\
\hline 1 & 1.5209287 & 1.474108648 & 1.679254235 & 1.214397822 \\
\hline 2 & 1.3209776 & 1.239505672 & 1.46949884 & 1.167146 \\
\hline 3 & 1.2686133 & 1.075718646 & 1.23038785 & 1.0062123 \\
\hline
\end{tabular}


International Journal of Research in Advent Technology, Vol.7, No.4, April 2019

E-ISSN: 2321-9637

Available online at www.ijrat.org

\begin{tabular}{|l|c|c|c|c|}
\hline 150 & 0.978344 & 1.300522795 & 1.09757583 & 0.7036245 \\
\hline 151 & 0.6190832 & 0.803663269 & 0.81985509 & 0.5001718 \\
\hline 152 & 0.5617708 & 0.67580369 & 0.69949915 & 0.4301079 \\
\hline 150 & 0.978344 & 1.300522795 & 1.09757583 & 0.7036245 \\
\hline 213 & 2.0086433 & 1.723257138 & 1.59245762 & 1.4589382 \\
\hline 214 & 1.8596289 & 1.433407055 & 1.39022923 & 1.2264661 \\
\hline 215 & 1.4419635 & 1.182887138 & 1.01237944 & 0.9188078 \\
\hline
\end{tabular}

HUMAN ENERGY FOR FERROUN AND NONFERROUS MATERIAL WTH ALL VARIABLES

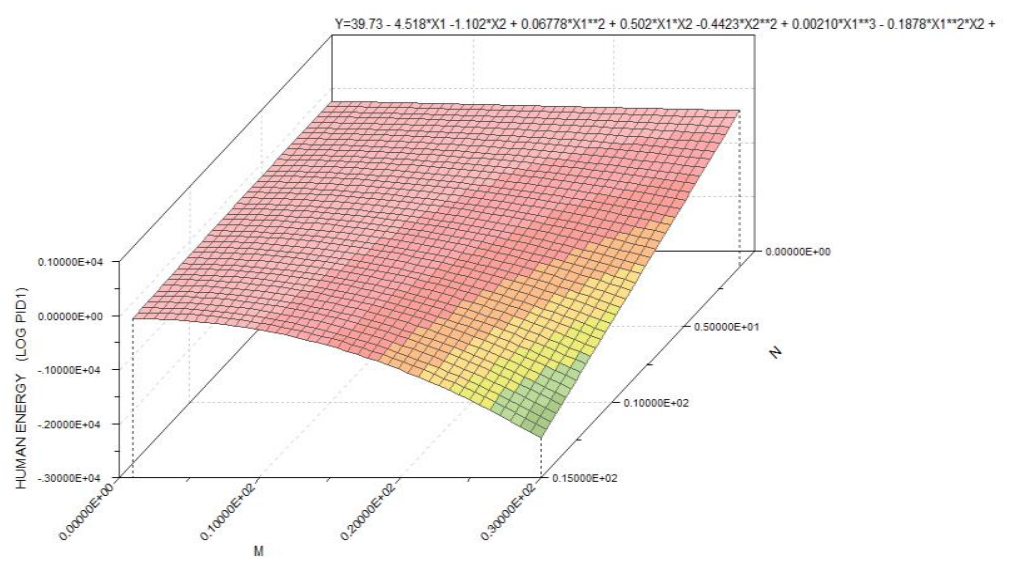

Fig 4a.

HUIAN ENERG VOR FERROUS IIATERHLL WTH ALL VARIABLES

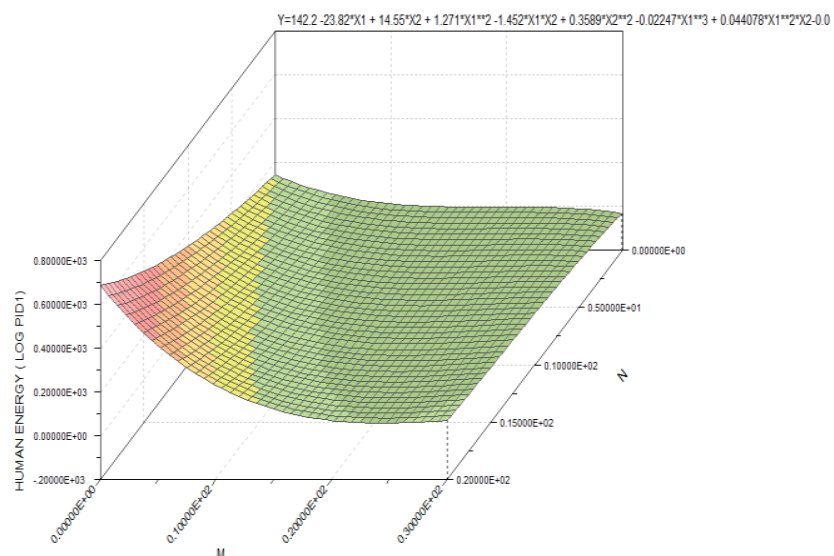

Fig 4b. 
International Journal of Research in Advent Technology, Vol.7, No.4, April 2019

E-ISSN: 2321-9637

Available online at www.ijrat.org

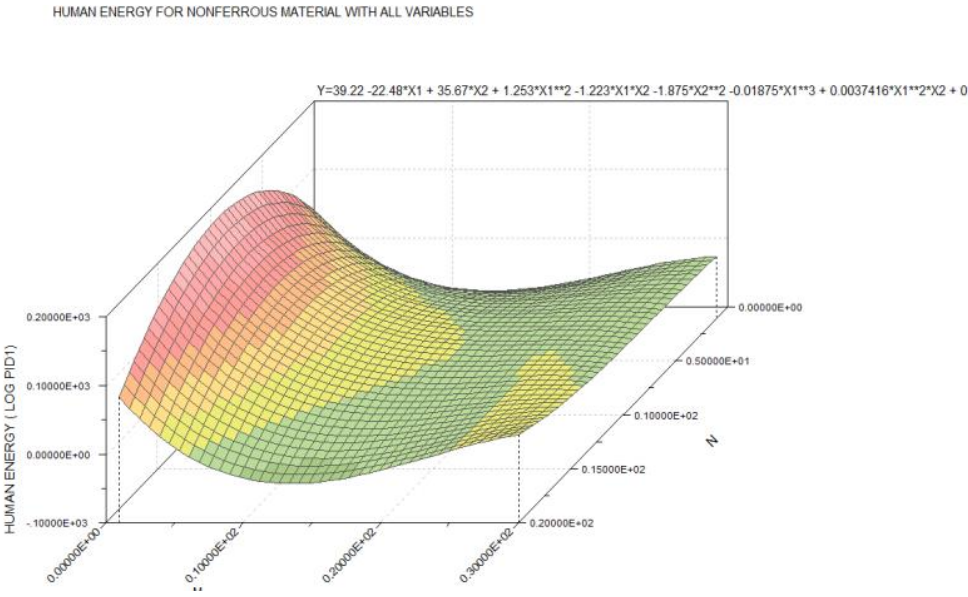

Fig 4c.

Figure 4. Response Surface Model for Human Energy (a) For machining ferrous and Nonferrous Materials (b) For Machining Ferrous material $\quad$ (c) For Machining Non Ferrous material

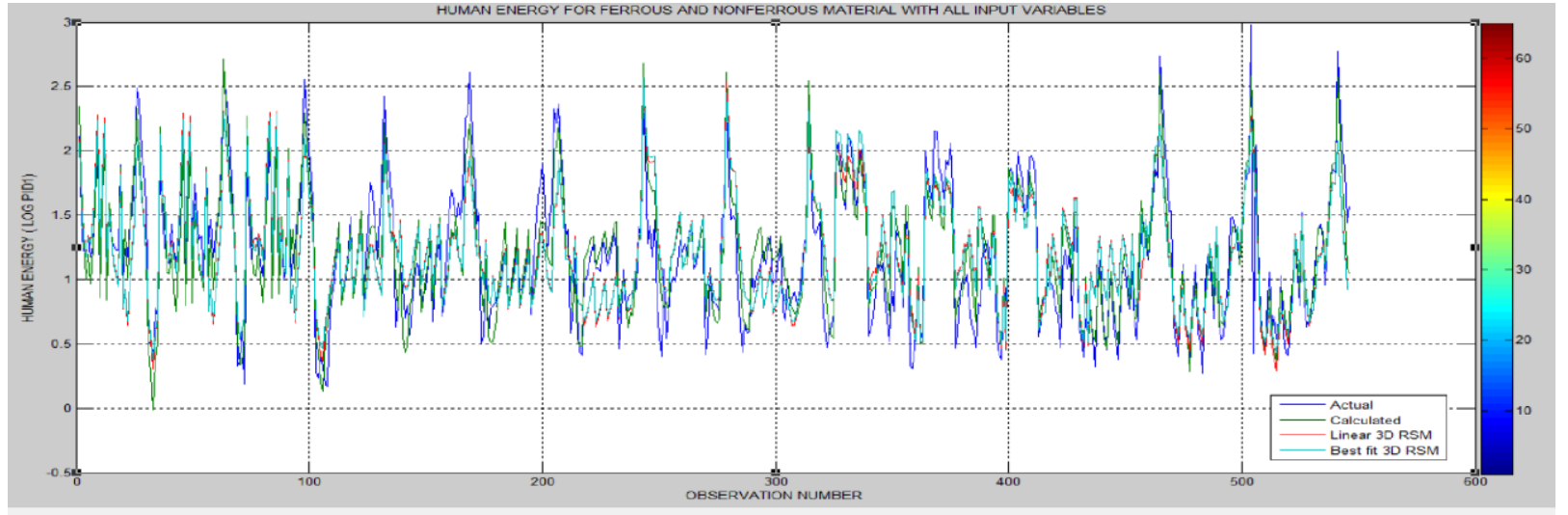

Fig 5a.

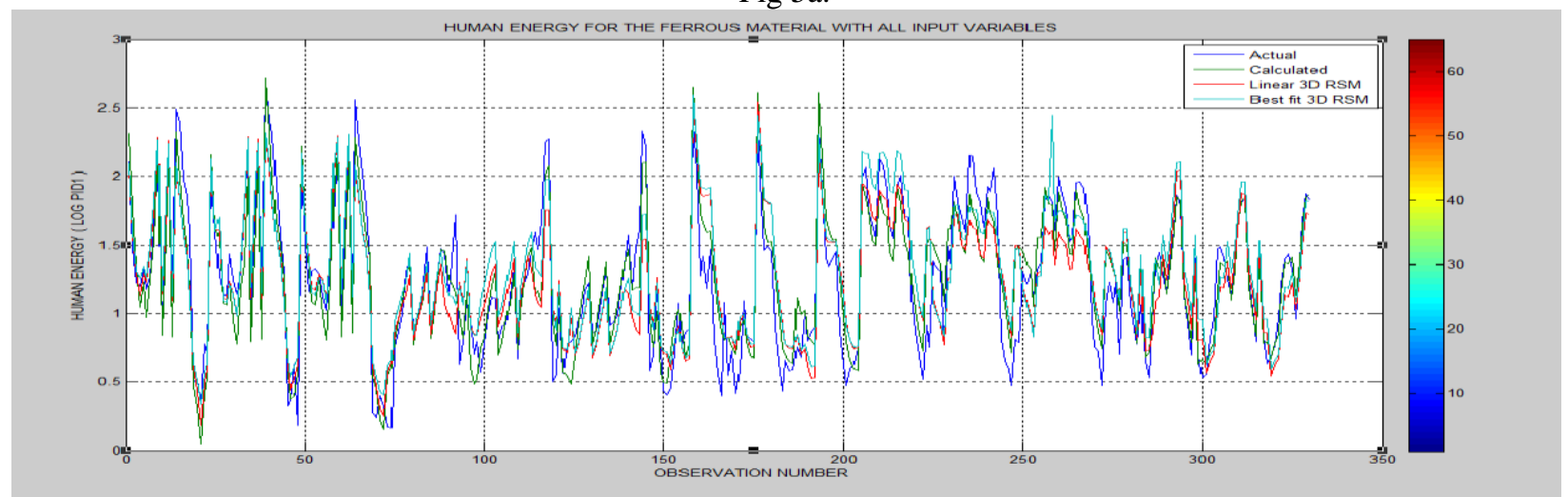

Fig $5 b$. 


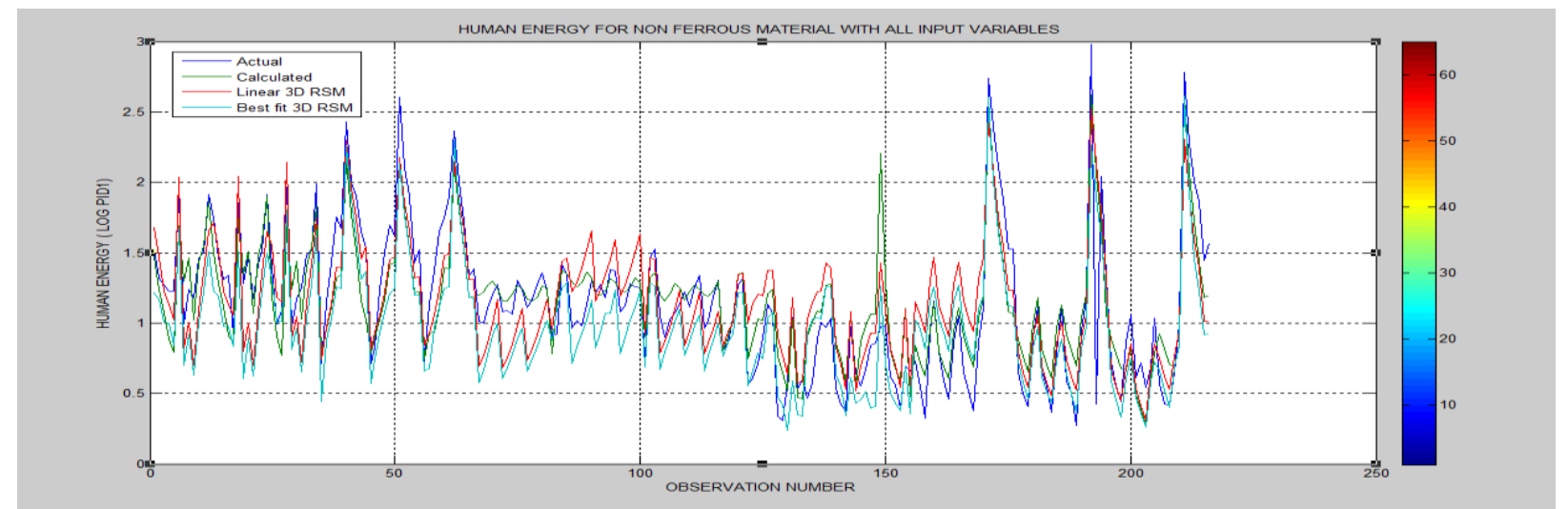

Fig 5c.

Figure 5. Comparison between actual, Calculated, Linear RSM and Beat fit REM for Human Energy (a) For ferrous and Nonferrous Materials (b) For Ferrous material $\quad$ (c) For Non Ferrous material

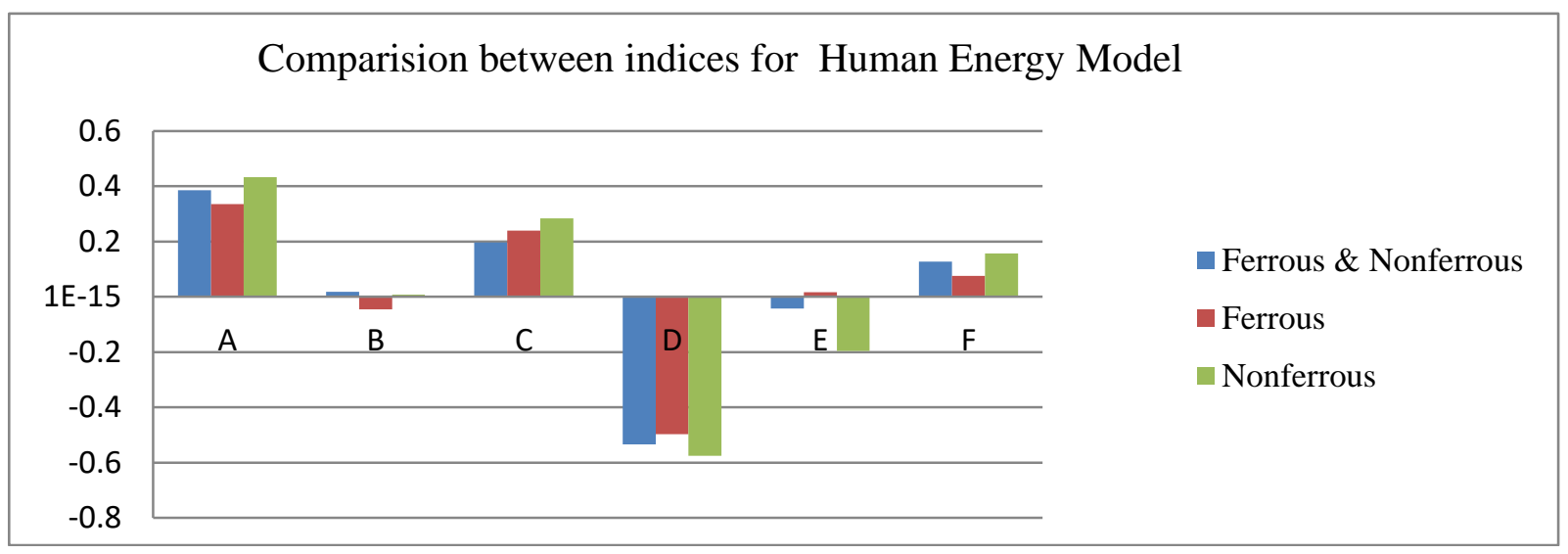

Figure 6. Comparison between indices for Ferrous \& Nonferrous, Ferrous and Nonferrous material

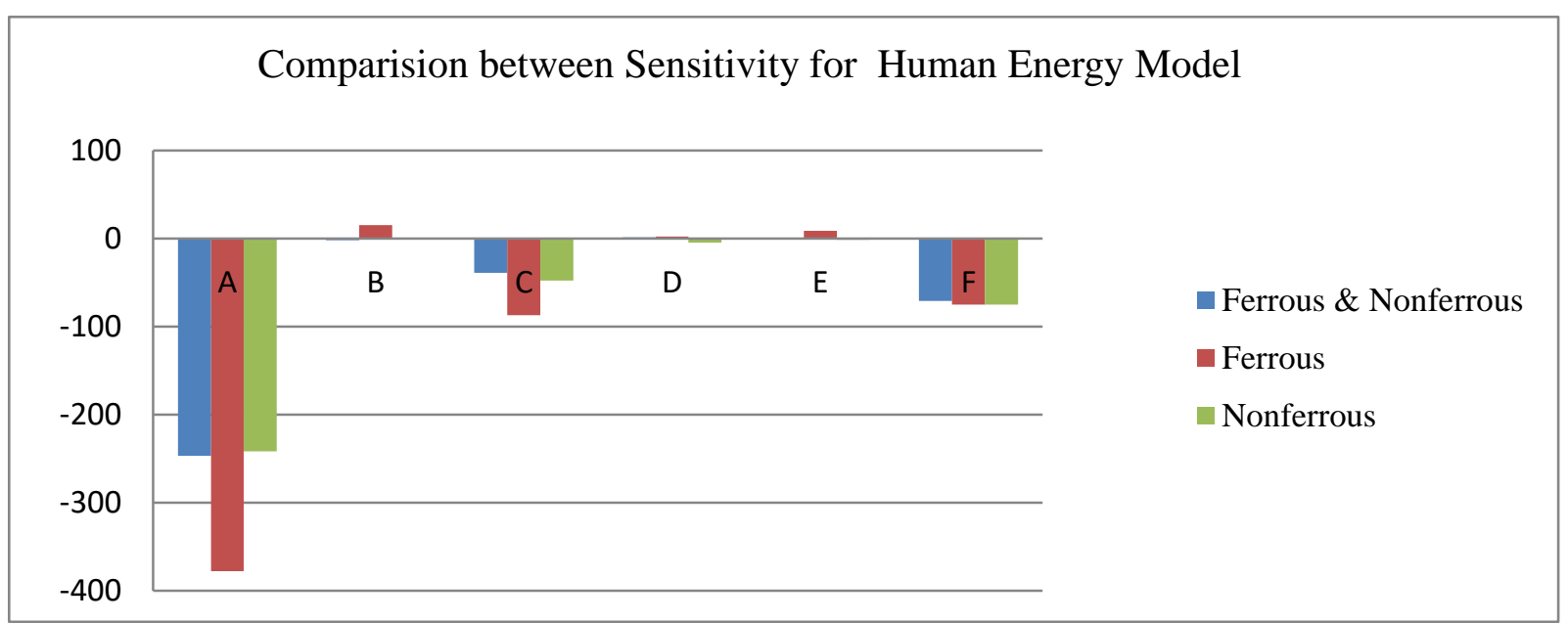

Figure 7. Comparison between Sensitivity for Ferrous \& Nonferrous, Ferrous and Nonferrous material 